Acta Theriologica $36(1-2): 87-94,1991$.

PL ISSN $0001-7051$

\title{
Population and habitat characteristics of two sympatric species of Ctenomys (Rodentia: Octodontidae)
}

\author{
Ana I. MALIZIA, Aldo I. VASSALLO and Cristina BUSCH
}

Malizia A. I., Vassallo A. I. and Busch C. 1991. Population and habitat characteristics of two sympatric species of Ctenomys (Rodentia: Octodontidae). Acta theriol. 36: 87 - 94.

Demography, spatial distribution, body size and habitat characteristics of two sympatric species of Ctenomys have been studied seasonally at Necochea (Buenos Aires Province, Argentina). Densities were 11.3 individuals/ha for Ctenomys talarum and 5.2 indiv./ha for Ctenomys australis. Breeding was seasonal for both species. Sex ratios were unbalanced in favour of females in C. australis while there were not significant differences between sexes in C. talarum. The spatial distribution for both populations was clumped and related to habitat characteristics. C. talarum was found in areas with higher plant biomass and harder soils, while $C$. australis was restricted to the areas with lower plant biomass and less compact soils. Spatial separation of these two species may be caused by different commitment to life underground resulting from differences in body size and energetics. Two possible explanations for the spatial distribution of C.australis and C. talarum are given.

Dept. Biología, Facultad de Ciencias Exactas y Naturales, Universidad Nac. de Mar del Plata, Casilla de Correo 1245, 7600 Mar del Plata, Argentina

Key words: demography, reproduction, habitat, coexistence, Ctenomys australis, C. talarum, Argentina

\section{Introduction}

Fossorial rodents of the genus Ctenomys, commonly termed tuco-tucos, are among the most geographically variable mammals, being the most important genus according to number of species of subterranean rodents (Reig et al. 1990).

The evolutionary process in a subterranean ecotope, which is characterized by its simplicity, stability and predecibility, leads to an adaptive convergence. The major evolutionary determinants of this convergence are specialization, competition and isolation acting between and within species (Nevo 1979, 1982).

As in other subterranean rodents, tuco-tucos show disjunts areas of distribution. Only one case of sympatry has been recorded, and that is in Monte Hermoso (Buenos Aires Province) between Ctenomys australis and Ctenomys talarum (Contreras and Reig 1965). In the present study, we found that the distribution of these two species also overlaps further to the north at Necochea (Buenos Aires Province) where previously only $C$. australis was recorded.

In the zone where $C$. australis and $C$. talarum are sympatric we hypothesize the development of life history traits and habitat selection mechanism that would prevent strong competitive interactions.

In this study we provide completely unknown information on demography, habitat characteristics, reproduction and body size in two sympatric species of Ctenomys with the aim of understanding how they coexist. 


\section{Study area}

The study site is a $4-10 \mathrm{~km}$ wide coastal dune fringe which grades into the inland grassland, presently cultivated. The dune fringe is generally diagonal (Frenguelli 1928) and exhibits a vegetation cover of about $20 \%$, composed mainly of Poa sp., Panicum racemosum and Calystelgia soldanella. The sand dunes reach altitudes ranging from 30 to $50 \mathrm{~m}$, above sea level, and extend 200 to $2000 \mathrm{~m}$ (Frenguelli 1928).

In the interdune areas, humid conditions prevailed allowing the development of a more dense vegetation cover (up to 80\%). Dominant vegetation was: Adesmia sp., Stipa tricotoma, Stipa neesiana and Bromus unioloides. In these interdune depressions, thin soil is overlaying calcrete layers, locally known as "tosca". The alternation of dunes and interdunes areas, each one with different topography and vegetation patterns, can be considered as typical patchy-like environment.

\section{Methods}

From November 1987 to October 1988, 69 Ctenomys australis (C. a.) and 59 Ctenomys talarum (C. t.) were captured during four seasonal trappings. The captures took place in four different areas. These areas were staked in a grid pattern with the stakes spaced $20 \mathrm{~m}$ apart, one coordinate was indicated on the stakes by numbers, the other by letters. Exact trap site could thus be recorded. Snap traps Oneida-Victor No. 0 and plastics traps were placed at the entrances of the burrows to catch all animals present in the areas.

When a tuco-tuco was captured, the trap position was carefully estimated to the nearest meter on both coordinates and written on a map. This schedule allowed us to determine density and spatial distribution of both species.

All animals were autopsied to obtain information on reproductive condition, sex ratio, number of embryos and relative age. Females were classified as immatures (uterus threadlike, close vagina and no follicular activity) and mature (open or plugged vagina and ripe follicles). Pregnancy or post-partum pregnancy was also noted. The latter was determined from the period of overlap of visible pregnancy and lactation or placental scars. Males were also classified as immatures (seminal vesicles attached to the defferent ducts and lack of spermatozoa in epididymus). All these criteria were based on those from Pearson et al. (1968) and Malizia and Busch (in press). Relative age of animals was determined on the basis of dry weights of eye lens (Lord 1959).

Environmental variables (aboveground and belowground plant biomass, plant cover, percent of clay-loam fraction, soil moisture, depth and compaction) were measured from samples $(n=54)$ taken near burrows for the purpose of characterizing habitat preferences of both species. Aboveground and belowground plant biomass were estimated by dry weight of extracted vegetation samples of $30 \mathrm{~cm}$ diameter and $30 \mathrm{~cm}$ belowground depth. Plant cover was measured on $0.25 \mathrm{~m}^{2}$ square using an ocular estimate method (Daubenmire 1959). Soil compaction was measured using a soil penetrometer and soil moisture was determined by differential weightings before and after drying the soil samples. Clay-loam fractions were separated using a sieve set.

An NTSYS Principal Component Analisis (PCA) program, through a correlation matrix to generate a reduced set of orthogonal vectors from original variables was performed. Results are given as $\bar{x} \pm S$ E. Student's $t$-tests and $\chi^{2}$ were used to analyze differences between means and frequencies, respectively.

\section{Results}

\section{Density and spatial distribution}

During the period of the study (November 1987 - October 1988) the average densities (without considering lactating individuals captured in the mother's burrow) were $11.32 \pm 2.56$ and $5.15 \pm 0.76$ individuals/ha for Ctenomys talarum and Ctenomys australis, respectively. $C$. $t$. had a peak density in autumn (June) whereas for $C$. $a$. highest numbers of individuals were recorded in spring (December) (Table 1). 
Table 1. Seasonal densities (individuals/ha) of Ctenomys talarum and Ctenomys australis.

\begin{tabular}{lrrrc}
\hline Species & Spring & Summer & Autumn & Winter \\
\hline C. talarum & 10.7 & 12.7 & 17.0 & 4.6 \\
C. australis & 7.4 & 4.5 & 4.0 & 4.6 \\
\hline
\end{tabular}

Poisson distribution analysis indicated that both species had a clumped distribution $(p<0.05)$. Distance between individuals was smaller $(p<0.01)$ in $C . t$. than in $C$. $a$; ; distance to nearest neighbour was $14.56 \mathrm{~m} \pm$ $1.32(n=55)$ and $20.79 m \pm 1.49(n=40)$, respectively. Interspecific distance to nearest neighbour was $17.12 \mathrm{~m} \pm 1.28(\mathrm{n}=43)$.

\section{Habitat characteristics}

Spatial distribution of populations was related to habitat characteristics as expressed by different soils and vegetation preferences. The PCA analysis used for the characterization of habitats of both species showed the following results:

Plant cover, soil compaction and plant biomass (aboveground and belowground) load positively on PC 1, while soil depth loads negatively on this vector. The PC 1 explained $58.9 \%$ of the total variance. In Table 2, correlation coefficients for each of the first three PC vectors and the original measurements are given.

Table 2. Correlation coefficients for original environmental variables and the first three principal components (PC) axes.

\begin{tabular}{lrrr}
\hline Variable & PC 1 & PC 2 & PC 3 \\
\hline Aboveground plant biomass & 0.664 & -0.391 & 0.602 \\
Belowground plant biomass & 0.859 & -0.225 & 0.144 \\
Soil compaction & 0.951 & 0.112 & -0.164 \\
Soil depth & -0.919 & -0.013 & 0.279 \\
Plant cover & 0.956 & -0.011 & -0.164 \\
Clay-loam fraction & 0.528 & 0.724 & 0.105 \\
Soil humidity & -0.042 & 0.907 & 0.233 \\
\hline
\end{tabular}

Soil moisture and percent of clay-loam fraction load positively on PC 2 , which explained $22.3 \%$ of total variance ( $81.2 \%$ cumulative). Only belowground biomass loaded on PC 3; this vector explained $8.3 \%$ of the variance $(89.5 \%$ cumulative).

The significance of these differences in environmental variables to discrimination among the habitat of both species, is evident from the bivariate PC plots (Fig. 1). One group was formed by soil and vegetation samples taken near $C$. $t$. burrows, and it is characterized by the highest plant biomass, plant cover and shallowest and hardest soils. All these traits are related to interdune areas. A second group was formed by samples taken near $C$. $a$. burrows, having a lower plant biomass, lower plant cover and deeper and less compact soils, which characterized dune zones. Although it seems to exist a sharp delimitation of both habitats occupied by $C$. $t$. and $C$. $a$., in zones where different soil and vegetation are intermingled this pattern is not clearly evident. 
Table 3 shows mean values and statistical significances for environmental variables measured for both species.

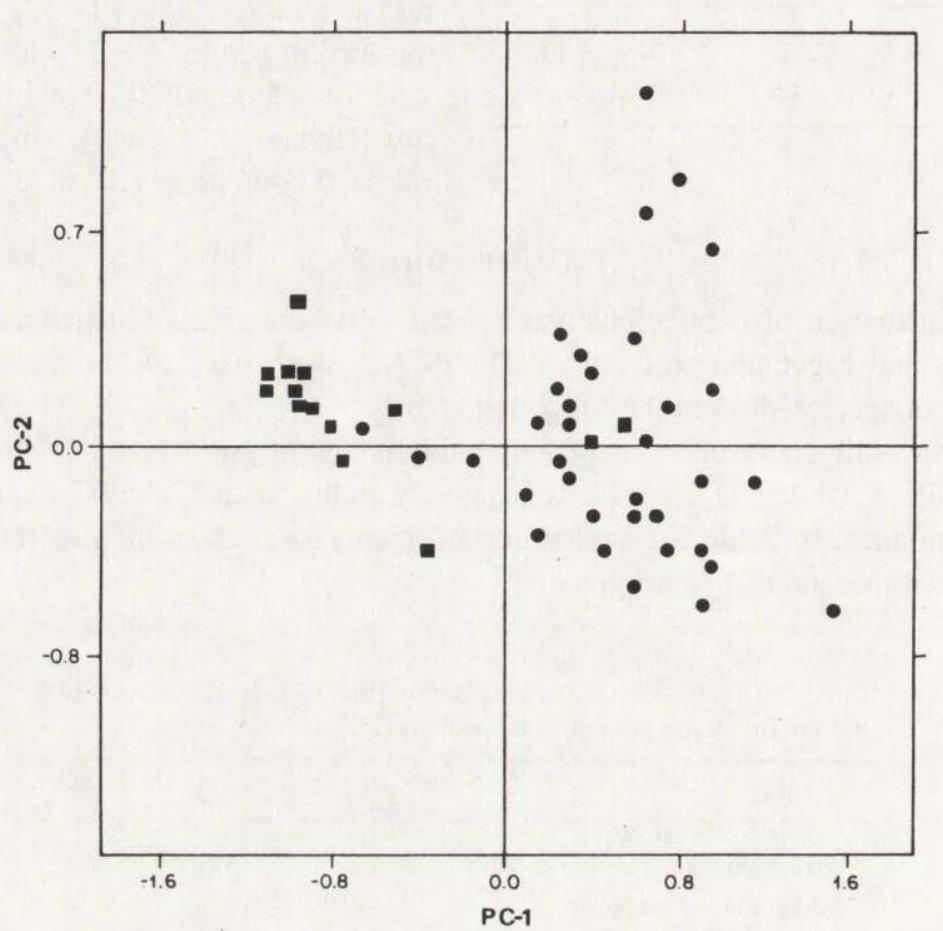

Fig. 1. Principal - component plot for soil and vegetation samples taken near burrows of Ctenomys talarum (circles) and Ctenomys australis (squares).

Table 3. Habitat variables measured for Ctenomys talarum and Ctenomys australis. Mean \pm S.E. are given.

\begin{tabular}{lrrc}
\hline Variable & C. australis & C. talarum & $p$ \\
\hline Plant cover (\%) & $29.7 \pm 5.6$ & $85.5 \pm 2.6$ & 0.001 \\
Soil depth $(\mathrm{cm})$ & $91.7 \pm 4.9$ & $34.8 \pm 2.4$ & 0.001 \\
Soil compaction $\left(\mathrm{kg} / \mathrm{cm}^{2}\right)$ & $6.9 \pm 1.6$ & $25.3 \pm 0.9$ & 0.001 \\
Clay-loam fraction (\%) & $0.2 \pm 0.0$ & $0.9 \pm 0.2$ & 0.01 \\
Soil humidity (\%) & $4.1 \pm 0.2$ & $3.6 \pm 0.3$ & $\mathrm{NS}$ \\
Aboveground plant biomass (g) & $4.8 \pm 0.9$ & $11.2 \pm 1.1$ & 0.001 \\
Belowground plant biomass (g) & $11.3 \pm 2.1$ & $25.5 \pm 1.7$ & 0.001 \\
\hline
\end{tabular}




\section{Reproductive characteristics}

Although males of both species of tuco-tucos showed a year round reproductive competence, breeding was seasonal. Fig. 2 shows the percentage of females in each sample exhibiting evidence of reproductive activity. Since there are no pregnant females in June and taking into account a mean gestation period of 102 days, estimated by Weir (1974) for $C$. $t$., and since at the end of winter (September) pregnant females were recorded with embryos in an advanced stage of development, we estimated that reproductive activity started in July. In March there are no $C$. $a$. pregnant females and only $12.5 \%$ of $C . t$. (1 in 8 ) were pregnant. Thus, the reproductive cycle reached the end of the summer.

Prevalence of pregnancy in C. $a$. peaked at the end of winter, when $100 \%(\mathrm{n}=10)$ of the females were pregnant. On the other hand, the highest activity for $C$. $t$. was recorded in spring, when $67 \%(\mathrm{n}=6)$ of the females were pregnant (Fig. 2). C. $a$. had a lower number of embryos/females than $C$. $t$. $(0.1<p<0.2)$. Mean number was $3.18 \pm 0.95$ and $4.17 \pm 1.94$ embryos/females for $C$. $a$. and $C$. $t$., respectively.

In spring $78 \%(\mathrm{n}=9)$ of the $C$. $a$. pregnant females were also lactating suggesting that this species has a post-partum pregnancy and two litters/year. On the other hand, there is no evidence of a post-partum pregnancy in $C$. $t$., since no female was recorded pregnant and lactating at the same time.

\section{Sex ratio}

Adult sex ratio, expressed as male/female + male, was unbalanced in favour of females in C. $a$. $($ sex ratio $=0.32 ; p<0.05 ; \mathrm{n}=47)$. In $C$. $t$., the sex ratio did not depart significantly from expected $0.5(0.51 ; p>0.5 ; \mathrm{n}=47)$. In both species subadult sex ratios were not different from the expected $0.5(p>0.25)$.

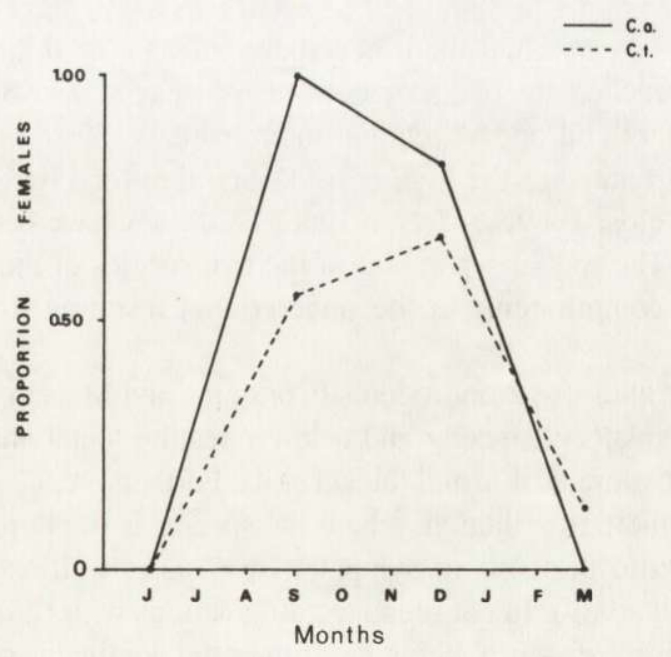

Fig. 2. Proportion of pregnant females of Ctenomys talarum and Ctenomys australis. 


\section{Sexual maturity and age structure}

Sexually mature $C$. $a$. are heavier than $250 \mathrm{~g}$ and their eye lens weighted more than $38 \mathrm{mg}$. C. $t$. talarum is smaller and matured at an average body weight of $95 \mathrm{~g}$ and $17 \mathrm{mg}$ eye lens weight. Both populations contain a high proportion of breeding adults; $80 \%(n=59)$ of $C$. $t$. and $68 \%(\mathrm{n}=69)$ of $C$. $a$. captured were adults. The high proportion of breeding adults found in both populations is a fact commonly reported for other subterranean mammals (Nevo 1982) and for C. $t$. in particular (Busch et al. 1989).

\section{Relationships between body length and weight}

Body weight and body length are shown in Table 4. C. $a$. is 3 times heavier and 1.5 longer than $C$. $t$. Males of both species are heavier than females, but not longer.

Table 4. Intraspecific body size relationships for adults of Ctenomys talarum and Ctenomys australis. Mean values \pm S.E. and sample size (in parenthesis) are given.

\begin{tabular}{|c|c|c|c|c|c|c|}
\hline \multirow[b]{2}{*}{ Measurement } & \multicolumn{2}{|c|}{ C. australis } & \multirow[b]{2}{*}{$p$} & \multicolumn{2}{|c|}{ C. talarum } & \multirow[b]{2}{*}{$p$} \\
\hline & $\begin{array}{l}\text { females } \\
(\mathrm{n}=32)\end{array}$ & $\begin{array}{c}\text { males } \\
(n=12)\end{array}$ & & $\begin{array}{l}\text { females } \\
(n=22)\end{array}$ & $\begin{array}{c}\text { males } \\
(n=24)\end{array}$ & \\
\hline Total length (mm) & $280.1 \pm 2.4$ & $297.3 \pm 9.2$ & $<0.05$ & $197.9 \pm 2.4$ & $207.4 \pm 2.2$ & $<0.01$ \\
\hline Body length (mm) & $187.4 \pm 2.1^{1}$ & $195.4 \pm 9.2$ & NS & $139.9 \pm 2.2$ & $144.4 \pm 1.8$ & NS \\
\hline Tail length (mm) & $93.1 \pm 0.9^{1}$ & $102.9 \pm 1.9$ & $<0.01$ & $57.9 \pm 1.2$ & $62.9 \pm 0.9$ & $<0.01$ \\
\hline Body weight (g) & $297.7 \pm 6.8^{2}$ & $425.3 \pm 19.8^{3}$ & $<0.01$ & $102.5 \pm 2.9$ & $134.6 \pm 3.7$ & $<0.001$ \\
\hline
\end{tabular}

${ }^{1} \mathrm{n}=31,{ }^{2} \mathrm{n}=21,{ }^{3} \mathrm{n}=12$

\section{Discussion}

Although trapping indicates that there is contact between $C$. $a$. and $C$. $t$. distributions in the coastal dunes of Necochea, the two species of tuco-tucos are distributed in a spatial pattern, corresponding to different soil and vegetation microhabitats. Since energetics and body size of fossorial rodents are related to the high cost of obtaining food by burrowing (Vleck 1979) and to thermal stress in closed caves (McNab 1966, 1979) they have been ascribed to particular environmental factors. The spatial separation of the two species of tuco-tucos may be caused, therefore, by different commitment to life underground resulting from differences in body size.

As it is reported for other fossorial rodents (Contreras and McNab 1990), the bigger C. $a$., with a better thermoregulatory capacity and a lower resting metabolic rate (Busch 1989), is restricted to the sandier, more friable and thicker soils. Furthemore, $C$. $t$. tolerates a wide range of soil types. In its northern distribution, where the species is in allopatry, it is found in both habitats, those occupied in the zone of sympatry by $C$. $t$. as well as by $C$. $a$. (Vassallo and Busch 1989, Busch et al. 1989). In consequence, interactions with $C$. $a$. would be a factor that affects $C$. $t$. distribution in Necochea, being the former the dominant species in the sand duncs.

Our results on average nearest neighbour distance (intra and interspecific) are related to burrow size (home range). Thus, we can infer that distances between interspecific burrows are 
no different from intraspecific burrow distances. These data suggest about the potential for actual interaction between both species.

On the other hand, our results show the existence of a post partum pregnancy and a higher proportion of pregnant females in $C$. $a$. This high reproductive potential may be adaptive for an habitat specialist whose dispersers would have a reduced probability of finding suitable habitats.

Laboratory experiments showed that males from an allopatric population of $C$. $t$. are more agressive than males from the sympatric one (Giannoni and Busch 1989). These results would explain the differences in adult sex ratio found between the allopatric population $(0.38$, males/females + males; Malizia and Busch, in press) and our data for the sympatric population (0.51, males/females + males).

The absence of $C$. $t$. in the sand dunes, may be the result of competitive exclusion. However, an alternative explanation could be the existence of an habitat selection mechanism, which would prevent strong competition. Thus, the competition could have been stronger in the past (Schroder and Rosenzweig 1975).

Further research to find out the causes of habitat differentiation are planned.

Acknowledgements: The authors wish to express their gratitude to Aldo Prieto for his assistance with computer programs and to the members of Laboratorio de Ecofisiología for their interest and encouragement. Financial support was provided by Consejo Nacional de Investigaciones Científicas y Técnicas (CONICET), PID N 3-1049006/88, granted to C. Busch and by grants from Universidad Nacional de Mar del Plata.

\section{References}

Busch C., Malizia A. I., Scaglia O. and Reig O. A. 1989. Spatial distribution and attributes of a population of Ctenomys talarum (Rodentia: Octodontidae). J. Mammal. 70: $204-208$.

Busch C. 1989. Metabolic rate and thermoregulation in two species of tuco-tuco Ctenomys talarum and Ctenomys australis (Caviomorpha, Octodontidae). Comp. Biochem. Physiol. 93: 345 - 347.

Contreras J. R. and Reig O. A. 1965. Datos sobre la distribución del género Ctenomys (Rodentia, Octodontidae) en la zona costera de la provincia de Buenos Aires comprendida entre Necochea y Bahía Blanca. Physis 25: $169-186$.

Contreras L. and McNab B. K. 1990. Energetics metabolism, body size and distribution in subterranean mammals. [In: Biology of subterranean mammals. E. Nevo and O. A. Reig, eds]. Allan Liss, New York.

Daubenmire R. 1959. A canopy-coverage method of vegetation analysis. Northw. Sci. 33: 43-66

Frenguelli J. 1928. Observaciones geológicas en la región costanera sur de la Provincia de Buenos Aires. Anales de la Facultad de Ciencias de la Educación, Paraná, Univ. Nac. del Litoral. 2: 1 - 45.

Giannoni S. M. and Busch C. 1989. Comportamiento agonístico y su relación con la distribución espacial de Ctenomys talarum. Resúmenes de la XIV Reunión Argentina de Ecología: 119.

Lord R. D. 1959. The lens as an indicator of age in cottontail rabbits. J. Wildl. Manage. 23: $358-360$.

McNab B. K. 1966. The metabolism of fossorial rodents: a study of convergence. Ecology 47: 712 - 732.

McNab B. K. 1979. The influence of body size on the energetics and distribution of fossorial and burrowing mammals. Ecology 60: 1010 - 1020.

Nevo E. 1979. Adaptive convergence and divergence in subterranean mammals. Ann. Rev. Ecol. Syst. 10: $269-308$.

Nevo E. 1982. Speciation in subterranean mammals. [In: Mechanisms of speciation. C. Barigozzi G. Montalenti and M. J. D. White, eds]. Liss. Publ., New York: $191-218$.

Pearson O., Binztein N., Boiry L., Busch C., DiPace M., Gallopin G., Penchaszadeh P. and Piantanida M. 1968. Estructura social, distribucion espacial y composicion por edades de una poblacion de tuco-tucos (Ctenomys talarum). Inv. Zool. Chilenas 13: $47-80$. 
Reig O. A., Busch C., Contreras J. and Ortells M. 1990. An overview of evolution, systematic, population biology and molecular biology in Ctenomys. [In: Biology of subterranean mammals. E. Nevo and O. A. Reig, eds]. Allan Liss, New York.

Schroder G. D. and Rosenzweig M. L. 1975. Perturbation analysis of competition and overlap in habitat utilization between Dipodomys ordii and Dipodomys merriami. Oecologia 19: 9 - 28.

Vassallo A. I. and Busch C. 1989. Diferencias ecológicas y en el tamaño corporal entre dos poblaciones de Ctenomys talarum en simpatría y alopatría. Resúmenes de la XIV Reunión Argentina de Ecología: 81.

Vleck D. 1979. The energy cost of burrowing by the pocket gopher Thomomys bottae. Physiol. Zool. 52: $122-134$.

Received 15 January 1990, accepted 30 May 1991. 